\title{
Pengaruh Experiential Marketing Terhadap Loyalitas Pelanggan Ritel Di Indonesia
}

\author{
Intan H Karuniatama $^{1}$, Dion D Barata ${ }^{2}$, Yohanes T Suyoto ${ }^{3}$ \\ ${ }^{1}$ Program Studi Manajemen, Universitas Pembangunan Jaya \\ intan.hajarkaruniatama@student.upj.ac.id \\ ${ }^{2}$ Program Studi Manajemen, Universitas Pembangunan Jaya \\ dion.dewa@upj.ac.id \\ ${ }^{3}$ Program Studi Manajemen, Universitas Pembangunan Jaya \\ totok.suyoto@upj.ac.id
}

Received 31 January 2020, Revised 8 March 2020, Accepted 29 March 2020

\begin{abstract}
The competition in retail industry becomes more dynamic and every organization need to develop new strategy to stand up in this competition. The objective of this research is to analyze the influence of experiential marketing on customer loyalty through customer satisfaction as intervening variable at retail industry in Indonesia. The research use 236 respondents as samples and collected by purposive sampling method. The obtained data then analyzed using Structural Equation Modeling (SEM) method through IBM SPSS AMOS 23 software. The result indicate that experiential marketing has positive and significant influence to customer satisfaction, customer satisfaction has positive and significant influence to customer loyalty, experiential marketing has positive and insignificant influence to customer loyalty, and customer satisfaction plays role as intervening variable between experiential marketing and customer loyalty. This result of this research could give a solid foundation for the organization to craft their impactful strategy in order to keep and stand up in the competition.
\end{abstract}

Keywords : Experiential, Satisfaction, Loyalty

\begin{abstract}
Abstrak - Kompetisi pada industri retail sangat dinamis dan dibutuhkan strategy baru agar organisasi dapat unggul dalam kompetisi tersebut. Tujuan penelitian ini adalah untuk menganalisa pengaruh experiential marketing terhadap loyalitas pelanggan melalui kepuasan pelanggan sebagai variabel intervening pada IKEA Alam Sutera. Data penelitian yang digunakan pada penelitian ini berjumlah 236 responden yang diambil dengan menggunakan purposive sampling. Data yang diperoleh selanjutnya diolah menggunakan metode analisis Structural Equation Modelling (SEM) dengan software IBM SPSS AMOS 23. Hasil penelitian menunjukkan bahwa experiential marketing memiliki pengaruh positif dan signifikan terhadap kepuasan pelanggan, kepuasan pelanggan memiliki pengaruh positif dan signifikan terhadap loyalitas pelanggan, experiential marketing memiliki pengaruh positif dan tidak signifikan terhadap loyalitas pelanggan, dan kepuasan pelanggan berperan sebagai variabel intervening antara experiential marketing dan loyalitas pelanggan. Hasil dari penelitian ini dapat menjadi dasar yang kuat bagi organisasi unutk menyusun strategi yang lebih berdampak terutama untuk tetap bertahan dan unggul dalam kompetisi saat ini.

Kata Kunci : Experiential, Kepuasan, Loyalitas
\end{abstract}

\section{LATAR BELAKANG}

Pada era globalisasi, semua sector kini dihadapkan pada persaingan yang sangat dinamis (Barata \& Napitupulu, 2019) dan Indonesia merupakan salah satu negara yang memiliki potensi besar dalam perkembangan industri ritel di dunia, dengan menduduki peringkat ke 5 dalam Indeks Perkembangan Ritel Global (GDRI) tahun 2019 yang dikeluarkan oleh ATKearny. Kuatnya persaingan industri ritel di Indonesia mengharuskan perusahaan memiliki strategi yang tepat dalam menarik pelanggan sehingga ritel dapat bertahan di dalam industri. Oleh karena itu, perusahaan harus dapat memiliki strategi agar dapat menghadapi persaingan yang kompetitif di dalam industri. Kesuksesan dalam persaingan akan dapat dipenuhi apabila perusahaan dapat menciptakan kepuasan pelanggan dan dapat mempertahankan pelanggan tersebut (Tjiptono, 2000) (dalam Rosita, 2015). Terutama dalam era globalisasi, perusahaan juga dituntut untuk mengembangkan strategi yang inovatif untuk 
menjaga daya saingnya dan selalu adaptif dengan kondisi yang ada (Barata, 2016).

Dalam menciptakan dua hal tersebut perusahaan dapat memberikan pelayanan yang baik melalui jasa, produk, fasilitas, dan suasana kepada pelanggan, dengan menerapkan hal tersebut perusahaan dapat menciptakan pengalaman berbelanja yang positif kepada pelanggan dan juga dapat menyentuh perasaan dan emosional pelanggan. Pine and Gilmore (1999) meramalkan bahwa pertumbuhan ekonomi masa depan terletak pada nilai pengalaman (Smith \& Hanover, 2016).

Fokus pada manfaat barang dan jasa saja tidaklah cukup karena pada era ekonomi baru pengalaman menjadi fenomena untuk mendapatkan pelanggan. Gaffar (2007) mengatakan bahwa sebuah pengalaman seseorang pada sebuah perusahaan dapat membentuk perilaku. Ketika pelanggan mendapatkan pelayanan yang baik dari perusahaan, maka pelanggan akan mengulangi perilaku pada perusahaan tersebut. Selain itu, melalui pengalaman perusahaan dapat membentuk hubungan jangka panjang kepada pelanggan, hubungan jangka panjang yang dimiliki oleh pelanggan akan memberi keuntungan kepada perusahaan.

Melalui experiential marketing perusahaan dapat memberikan pengalaman kepada pelanggan. Experiential marketing merupakan pengembangan dari strategi pemasaran tradisional yang mana didasari oleh keinginan pelanggan pada faktor produk, komunikasi, dan kampanye pemasaran yang dapat menghantarkan pengalaman (Schmitt \& Rhea, 2015). Schmitt (1999) (dalam Pangastuti, 2017) menyatakan experiential marketing adalah cara untuk menciptakan pengalaman yang akan dirasakan oleh pelanggan ketika menggunakan produk atau jasa melalui sense, feel, think, act, dan relate. Schmitt \& Zarantonello (2013) menyatakan experiential marketing dapat mempunyai keuntungan pada beberapa situasi seperti membangkitkan kembali merek yang mengalami penurunan, membedakan produk dengan produk kompetitor, menciptakan identitas perusahaan, mempromosikan inovasi, dan menciptakan loyalitas pelanggan terhadap suatu merek.

Sebelum perusahaan memiliki pelanggan yang loyal, perusahaan harus mampu menciptakan kepuasan pada diri pelanggan. Karena kepuasan pelanggan merupakan tujuan utama pada setiap perusahaan dalam menjalankan bisnis. Kepuasan secara keseluruhan dapat dihasilkan oleh pelanggan berdasarkan pada pembelian dan pengalaman mengkonsumsi barang dan jasa (Garbarino \& Johnson, 2001) (dalam Rosita, 2015). Menurut Kotler \& Keller (2016) kepuasan pelanggan adalah perasaan senang atau kecewa seseorang yang dihasilkan dari membandingkan kinerja (atau hasil) suatu produk atau layanan yang diharapkan. Dengan terciptanya kepuasan pada diri pelanggan, dapat menguntungkan perusahaan untuk memiliki pelanggan yang loyal. Reichheld \& Sasser (1990) (dalam Budiarta \& Fachira, 2017) mendefinisikan pelanggan yang loyal merupakan pelanggan yang menghargai sebuah hubungan yang dimiliki dengan perusahaan secara memadai untuk menjadikan perusahaan tersebut sebagai perusahaan penyedia yang disukai.

Pelanggan yang loyal tidak akan beralih pada suatu perusahaan hanya karena perusahaan memiliki perbedaan kecil, seperti harga dan layanan. Sebaliknya pelanggan yang loyal tidak segan untuk memberikan feedback yang jujur dan produktif kepada perusahaan, mereka menggabungkan volume dari kategori pembelian mereka dengan perusahaan, memperlakukan karyawan perusahaan dengan baik, dan antusias dalam memberikan rekomendasi kepada kerabat dan teman-teman mereka (Shoemaker \& Bowen, 2003) (dalam Budiarta \& Fachira, 2017).

Dalam hal ini, perusahaan dapat menerapkan experiential marketing dalam memberikan pengalaman positif kepada pelanggan misalnya dengan memiliki display produk yang dapat dilihat, dicoba, dan disentuh pada setiap setting interior, fasilitas yang lengkap, pelayanan self-service, dan beragamnya jenis produk yang dimiliki dapat memberikan pengalaman tersendiri bagi setiap pelanggan. Experiential marketing ini menjadi sangatlah penting, karena setiap perusahaan membutuhkan strategi untuk bersaing dengan perusahaan ritel lainnya dan agar dapat bertahan di industri ritel, perusahaan dituntut untuk memiliki pelanggan yang loyal.

Adapun tujuan dari penelitian ini adalah sebagai berikut:

1. Untuk mengetahui apakah experiential marketing memiliki pengaruh terhadap kepuasan pelanggan.

2. Untuk mengetahui pengaruh kepuasan pelanggan tersebut terhadap loyalitas pelanggan.

3. Untuk mengethui apakah experiential marketing mempengaruhi loyalitas pelanggan

4. Untuk mengetahui pengaruh experiential marketing terhadap loyalitas pelanggan melalui kepuasan pelanggan

\section{KAJIAN PUSTAKA}

Menurut Schmitt (1999) experiential marketing merupakan cara untuk menciptakan pengalaman yang akan dirasakan oleh pelanggan ketika menggunakan produk atau jasa melalui sense, feel, think, act, dan relate (Pangastuti, 2017). Terdapat empat karakteristik dalam experiential marketing yaitu: Customer experiences, yang merupakan fokus utama dalam memberi alasan mengapa pelanggan harus melakukan pembelian melalui pandangan yang lebih luas. Pengalaman terjadi dikarenakan adanya pertemuan, menjalani, atau hidup melalui kejadian tertentu (Schmitt \& Rhea, 2015); Consumption as a holistic experience, yang berfokus terhadap produk yang sesuai dengan situasi pelanggan dan bagaimana produk, kemasan, dan media komunikasi dapat 
meningkatkan pengalaman pelanggan (Pangastuti, 2017); Customer as rational and emotional animal, yang memahami bahwa Pelanggan tidak hanya memiliki pandangan rasional, tapi juga memiliki pandangan emosional dalam memutuskan melakukan pembelian. Hal ini didorong karena pelanggan menginginkan pengalaman yang menyenangkan (Schmitt \& Rhea, 2015); dan Methods and tools are eclectic,yang menyatakan bahwa dalam mengukur experiential marketing terdapat metode yang berbeda dan beragam. Experiential marketing tidak terikat hanya dengan satu ideologi metodologi melainkan secara elektrik, beberapa metode dan alat mungkin sangat analitis dan kuantitatif, intuitif dan kualitatif, verbal, mengambil format tradisional secara terperinci, wawancara, kuesioner, dan visual (Schmitt \& Rhea, 2015).

Experiential marketing memiliki frame works Strategic Experiential Modules (SEMs). SEMs merupakan dasar dari experiential marketing untuk memberikan pengalaman kepada pelanggan (Eka \& Yuliana, 2016). Selanjutnya Alma (2013) (dalam Eka \& Yuliana, 2016) menjelaskan terdapat lima tahapan dalam SEMs yang ada pada experiential marketing: Tahap pertama adalah Sense, yaitu tahap saat perusahaan memberikan kesan keindahan, kesenangan, dan kepuasan dengan cara menciptakan sensory experience melalui penglihatan, suara, sentuhan, pengecapan, dan penciuman yang dihasilkan oleh panca indera. Sense berkaitan dengan simbol verbal maupun visual seperti desain interior, penampilan produk, musik, dan aroma yang dapat menciptakan pengalaman yang positif kepada pelanggan.

Tahap kedua adalah Feel, yaitu saat Perusahaan \ membangkitkan pengalaman afektif melalui inner feeling and emotions sehingga ada rasa gembira dan bangga bagi pelanggan. Kertajaya (2010) menyatakan feel berpengaruh dalam banyak hal menyangkut perilaku konsumen, karena feel berkaitan dengan emosi. Tahap ketiga adalah Think, yang dicapai melalui surprise, intrigue, dan provocation perusahaan dapat menciptakan aspek kognitif yaitu problem-solving experience. Think mengacu pada masa depan, fokus, nilai, kualitas, dan perkembangan dan dapat ditampilkan melalui aspek yang dapat memberikan inspirasi (Schmitt \& Rogers, 2008). Think memiliki tujuan untuk mendorong pelanggan, sehingga tertarik dan berpikir secara kreatif agar dapat menghasilkan evaluasi mengenai perusahaan dan merek tersebut.

Tahap keempat adalah Act, yang dapat menciptakan pengalaman pelanggan yang berhubungan dengan tubuh secara fisik, perilaku, gaya hidup jangka panjang, dan pengalaman yang terjadi dari interaksi dengan orang lain. Act dapat mengubah perilaku dan gaya hidup pelanggan dengan memberi motivasi untuk melakukan sebuah tindakan. Act memiliki tujuan untuk memberikan kesan terhadap pola perilaku dan gaya hidup, serta memperkaya pola interaksi sosial melalui strategi yang dilakukan. Tahap terakhir adalah Relate, sebagai gabungan dari sense, feel, think, dan act. Relate menunjukkan hubungan dengan orang lain, kelompok (seperti pekerjaan dan gaya hidup) atau komunitas sosial yang lebih luas dan abstrak (negara, masyarakat, budaya). Relate memiliki tujuan untuk menghubungkan pelanggan dengan budaya dan lingkungan sosial yang dicerminkan oleh merek suatu produk.

\section{Kepuasan Pelanggan}

Kotler and Keller (2016) menyatakan kepuasan pelanggan adalah perasaan senang atau kecewa seseorang yang dihasilkan dari membandingkan kinerja (atau hasil) suatu produk atau layanan yang diharapkan. Jika hasil yang diterima oleh pelanggan tidak sesuai dengan harapan, pelanggan akan tidak puas. Jika hasil yang diterima oleh pelanggan sesuai dengan harapan, pelanggan akan puas. Jika hasil yang diterima oleh pelanggan melebihi harapan, maka pelanggan akan sangat puas. Mowen dan Minor (2002) (dalam Dharmayanti \& Hadiwidjaja, 2015) menyatakan bahwa kepuasan pelanggan didefinisikan sebagai keseluruhan sikap yang ditunjukkan pelanggan atas barang atau jasa setelah pelanggan tersebut memperoleh dan menggunakannya.

Menurut Lupiyoadi (2001:158) (dalam Barimbing \& Sari, 2015) menyatakan terdapat 5 faktor utama dalam menentukan tingkat kepuasan pelanggan, yaitu Kualitas Produk saat Pelanggan merasa puas bila hasil evaluasi yang dihasilkan oleh pelanggan menunjukkan bahwa produk yang digunakan oleh pelanggan merupakan produk yang berkualitas, Kualitas Pelayanan,saat pelayanan yang baik dan sesuai dengan harapan pelanggan maka pelanggan akan merasa puas, Emosional saat nilai sosial yang didapat membuat pelanggan menjadi puas terhadap suatu merek, Harga saat Perusahaan yang wajar tetapi tetap memiliki kualitas baik dan sama dengan produk lain, dan Biaya yaitu saat pelanggan tidak perlu mengeluarkan biaya tambahan apapun untuk mendapatkan produk yang ingin dibelinya.

\section{Loyalitas Pelanggan}

Gramer \& Brown (dalam Zati \& Iqbal, 2017) menyatakan loyalitas adalah derajat sejauh mana seorang pelanggan menunjukkan perilaku pembelian berulang dari suatu penyedia jasa, memiliki suatu disposisi atau kecenderungan sikap positif terhadap penyedia jasa, dan hanya mempertimbangkan untuk menggunakan penyedia jasa ini pada saat muncul kebutuhan untuk memakai jasa ini. Berdasarkan definisi yang disampaikan oleh Gramer \& Brown, menunjukkan bahwa pelanggan yang loyal bukan hanya seorang pelanggan yang melakukan pembelian berulang, tetapi juga mempertahankan sikap positif terhadap penyedia jasa. Tjiptono (2010:107) (dalam 
Sari et al., 2017) menyatakan loyalitas pelanggan terbentuk karena pelanggan merasakan kepuasan dalam mengkonsumsi barang atau jasa. Loyalitas menggambarkan perilaku yang diharapkan sehubungan dengan produk atau jasa. Loyalitas pelanggan akan tinggi apabila suatu produk dinilai mampu memberi kepuasan tertinggi sehingga pelanggan enggan untuk beralih ke merek lain (Zati \& Iqbal, 2017)

Terdapat 4 karakteristik dalam loyalitas pelanggan menurut Griffin (2013) (dalam Dewi et al., 2015) yaitu: Pelanggan melakukan pembelian secara teratur atau pembelian ulang sebanyak dua kali atau lebih, Pelanggan yang melakukan pembelian antar lini produk dan jasa, Merekomendasikan produk dan jasa milik perusahaan kepada orang lain, dan adanya Ketidaktertarikan pada produk atau jasa dari merek perusahaan lain.

Berdasarkan penelusuran teori sebelumnya maka penelitian ini membahas hubungan experiential marketing terhadap loyalitas pelanggan melalui kepuasan pelanggan, yang terlihat melalui kerangka pemikiran dari penelitian ini yaitu:

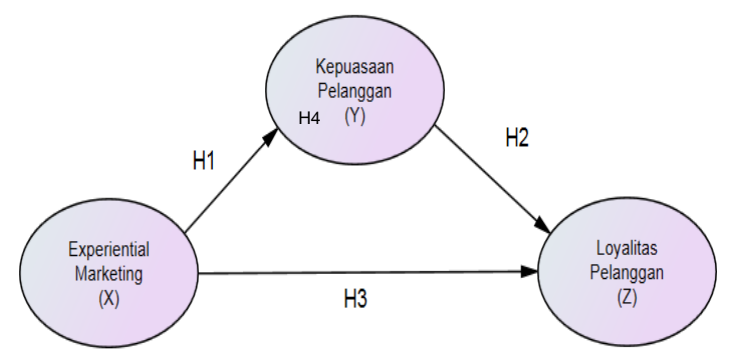

Gambar 1. Kerangka Pemikiran

Berdasarkan kerangka pemikiran diatas, sehingga dapat dirumuskan hipotesis sebagai berikut: H1: Experiential marketing memiliki pengaruh terhadap kepuasan pelanggan.

H2: Kepuasan pelanggan memiliki pengaruh terhadap loyalitas pelanggan.

H3: Experiential marketing memiliki pengaruh terhadap loyalitas pelanggan.

H4: Experiential marketing berpengaruh terhadap loyalitas pelanggan melalui kepuasan pelanggan.

\section{METODE PENELITIAN}

Jenis penelitian ini merupakan penelitian explanatory research, yang dilakukan di salah satu perusahaan ritel besar di Indonesia. Populasi yang digunakan sebanyak 219.551 orang, yang merupakan rata-rata jumlah pelanggan dalam tiga bulan. Teknik pengambilan sampel menggunakan teknik purposive sampling dengan sampel sebanyak 250 responden, berusia dari 19 tahun sampai pelanggan dengan usia lebih dari 49 tahun, dan sudah memiliki pengalaman bertransaksi setidaknya tiga kali pada perusahaan ritel yang sama.
Skala pengukuran pada penelitian ini menggunakan skala Likert 1 sampai 6. Pada uji validitas factor loading yang digunakan untuk mendapatkan hasil yang signifikan sebesar 0.50 dan pada uji reliabilitas menggunakan uji Cronbach's Alpha dengan nilai $\alpha>0.70$. Metode analisis yang digunakan dalam penelitian ini yaitu Structural Equation Model (SEM) dengan menggunakan software IBM SPSS AMOS 23.

Pada penelitian ini menggunakan uji-T untuk menguji hasil hipotesis pada penelitian ini, Dengan membandingkan nilai $\mathrm{T}$ hitung dengan masingmasing variabel bebas untuk $\mathrm{T}$ tabel pada $\alpha=0.05$, nilai $\mathrm{T}$ yang didapat sebesar 1,96 karena jumlah sampel yang didapat lebih dari 120. Pada goodness of fit derajat kecocokan yang digunakan adalah GFI (Goodness of Fit Index), RMSEA (Root Mean Square Error of Approximation), CFI (Comparative Fix Index), dan Normed Chi-square.

\section{HASIL PENELITIAN DAN ANALISIS}

Setelah dilakukan penyebaran kuesioner dan dilakukannya data screening didapatkan data sebanyak 236 dari 250 kuesioner yang dibagikan, untuk digunakan pada tahap selanjutnya.

\section{Karakteristik Responden}

Tabel 1 memperlihatkan karakterisatik responden dalam penelitian ini.

Tabel 1. Karakteristik Responden

\begin{tabular}{|c|c|c|c|}
\hline \multirow{2}{*}{ No } & \multirow{2}{*}{$\begin{array}{l}\text { Karakteristik } \\
\text { Responden }\end{array}$} & \multicolumn{2}{|c|}{ Total Responden } \\
\hline & & Jumlah & Persentase \\
\hline \multicolumn{4}{|c|}{ Jenis Kelamin } \\
\hline 1 & Wanita & 147 & $62 \%$ \\
\hline 2 & Pria & 89 & $38 \%$ \\
\hline \multicolumn{4}{|c|}{ Usia } \\
\hline 1 & 19-28 tahun & 109 & $46 \%$ \\
\hline 2 & 29-38 tahun & 78 & $33 \%$ \\
\hline 3 & 39-48 tahun & 37 & $16 \%$ \\
\hline 4 & $>49$ tahun & 12 & $5 \%$ \\
\hline \multicolumn{4}{|c|}{ Pekerjaan Responden } \\
\hline 1 & Pelajar/ mahasiswa & 46 & $20 \%$ \\
\hline 2 & Pegawai Swasta & 87 & $37 \%$ \\
\hline 3 & Pegawai Negeri & 29 & $12 \%$ \\
\hline 4 & Ibu Rumah Tangga & 33 & $14 \%$ \\
\hline 5 & Wirausaha & 41 & $17 \%$ \\
\hline \multicolumn{4}{|c|}{ Rata-rata Pengeluaran Per Bulan } \\
\hline 1 & $<1$ juta & 34 & $14 \%$ \\
\hline 2 & $1-5$ juta & 122 & $52 \%$ \\
\hline 3 & 5-10 juta & 68 & $29 \%$ \\
\hline 4 & $>10$ juta & 12 & $5 \%$ \\
\hline \multicolumn{4}{|c|}{ Jumlah Kunjungan } \\
\hline 1 & $>3$ kali & 162 & $69 \%$ \\
\hline 2 & 2 kali & 49 & $21 \%$ \\
\hline 3 & 1 kali & 25 & $10 \%$ \\
\hline \multicolumn{4}{|c|}{ Jumlah Kunjungan } \\
\hline 1 & $>3 \mathrm{kali}$ & 142 & $60 \%$ \\
\hline 2 & 2 kali & 46 & $20 \%$ \\
\hline 3 & 1 kali & 48 & $20 \%$ \\
\hline
\end{tabular}

\section{Uji Validitas}


Pada penelitian ini menggunakan nilai hasil factor loading minimal 0.50 pada tiap indikator untuk dinyatakan valid. Hasil uji validitas dapat dilihat pada Tabel 2 .

Tabel 2. Hasil Uji Validitas

\begin{tabular}{|c|c|c|c|}
\hline Indikator & $\begin{array}{l}\text { Item } \\
\text { Pernya- } \\
\text { taan }\end{array}$ & $\begin{array}{l}\text { Factor } \\
\text { Loading }\end{array}$ & $\begin{array}{l}\text { Kete- } \\
\text { rangan }\end{array}$ \\
\hline \multicolumn{4}{|l|}{ Experiental Marketing } \\
\hline Design interior & $\mathrm{P} 1 \mathrm{X}$ & 0.80 & Valid \\
\hline Penampilan produk & $\mathrm{P} 2 \mathrm{X}$ & 0.83 & Valid \\
\hline Pemilihan musik & P3X & 0.79 & Valid \\
\hline Aroma di dalam toko & $\mathrm{P} 4 \mathrm{X}$ & 0.66 & Valid \\
\hline Kebersihan dan & P5X & 0.83 & Valid \\
\hline kerapian toko & P6X & 0.76 & Valid \\
\hline Sikap pegawai & P7X & 0.80 & Valid \\
\hline Akses lokasi & P8X & 0.68 & Valid \\
\hline $\begin{array}{l}\text { Keberagaman produk } \\
\text { yang disediakan }\end{array}$ & P9X & 0.82 & Valid \\
\hline $\begin{array}{l}\text { Kesesuaian harga } \\
\text { dengan kualitas barang } \\
\text { dan jas }\end{array}$ & P10X & 0.72 & Valid \\
\hline Informasi mengenai & $\mathrm{P} 11 \mathrm{X}$ & 0.83 & Valid \\
\hline produk dan toko & $\mathrm{P} 12 \mathrm{X}$ & 0.83 & Valid \\
\hline $\begin{array}{l}\text { Pelayanan yang } \\
\text { diberikan }\end{array}$ & $\mathrm{P} 13 \mathrm{X}$ & 0.87 & Valid \\
\hline $\begin{array}{l}\text { Penanganan keluhan } \\
\text { yang diberikan }\end{array}$ & $\mathrm{P} 14 \mathrm{X}$ & 0.83 & Valid \\
\hline $\begin{array}{l}\text { Identitas perusahaan } \\
\text { Kepuasan Pelanggan }\end{array}$ & P15X & 0.76 & Valid \\
\hline \multirow{2}{*}{ Kualitas produk } & P1Y & 0.87 & Valid \\
\hline & $\mathrm{P} 2 \mathrm{Y}$ & 0.89 & Valid \\
\hline \multirow{2}{*}{ Kualitas pelayanan } & P3Y & 0.85 & Valid \\
\hline & P4Y & 0.86 & Valid \\
\hline \multirow{2}{*}{ Perasaan Senang } & P5Y & 0.87 & Valid \\
\hline & P6Y & 0.84 & Valid \\
\hline $\begin{array}{l}\text { Kesesuaian Harga } \\
\text { Loyalitas }\end{array}$ & P7Y & 0.90 & Valid \\
\hline $\begin{array}{l}\text { Melakukan pembelian } \\
\text { ulang }\end{array}$ & $\mathrm{P} 1 \mathrm{Z}$ & 0.83 & Valid \\
\hline Mengatakan hal positif & $\mathrm{P} 2 \mathrm{Z}$ & 0.89 & Valid \\
\hline $\begin{array}{l}\text { Merekomendasikan } \\
\text { produk dan jasa } \\
\text { kepada orang lain }\end{array}$ & P3Z & 0.89 & Valid \\
\hline \multirow{2}{*}{$\begin{array}{l}\text { Ketidaktertarikan pada } \\
\text { merek lain }\end{array}$} & $\mathrm{P} 4 \mathrm{Z}$ & 0.86 & Valid \\
\hline & P5Z & 0.80 & Valid \\
\hline
\end{tabular}

Berdasarkan hasil analisis pada Tabel 2, pada variabel X yaitu experiential marketing terdapat 15 item pernyataan yang dinyatakan valid dengan memperoleh factor loading terendah 0.66 pada indikator P4X. Pada variabel $\mathrm{Y}$ yaitu kepuasan pelanggan, terdapat 7 item pernyataan yang dinyatakan valid dengan nilai factor loading terendah 0.84 pada dua indikator yaitu P6Y. Pada variabel $\mathrm{Z}$ yaitu loyalitas pelanggan, dinyatakan valid pada kelima pernyataan dengan nilai factor loading terendah yaitu 0.80 pada indikator P5Z.

\section{Uji Reliabilitas}

Pada uji reliabilitas, penelitian ini menggunakan uji Cronbach's Alpha dengan nilai $\alpha>$ 0.70 pada tiap variabel untuk dinyatakan reliabel. Hasil uji reliabilitas dapat dilihat pada Tabel 3.

Tabel 3. Hasil Uji Reliabilitas

\begin{tabular}{ccc}
\hline Variabel & $\begin{array}{c}\text { Nilai Cronbach's } \\
\text { Alpha }\end{array}$ & $\begin{array}{c}\text { Keterangan } \\
\text { Reliabilitas }\end{array}$ \\
\hline $\begin{array}{c}\text { Experiential } \\
\text { marketing }\end{array}$ & 0,957 & $\begin{array}{c}\text { Sangat } \\
\text { Reliabel } \\
\text { Kepuasan } \\
\text { pelanggan }\end{array}$ \\
$\begin{array}{c}\text { Loyalitas } \\
\text { Pelanggan }\end{array}$ & 0,946 & $\begin{array}{c}\text { Reliabel } \\
\text { Sangat } \\
\text { Reliabel }\end{array}$ \\
\hline
\end{tabular}

Berdasarkan hasil uji reliabilitas field-test pada Tabel 3 variabel experiential marketing dinyatakan reliabel karena memiliki nilai Cronbach's Alpha sebesar 0.957, variabel kepuasan pelanggan diperoleh nilai Cronbach's Alpha sebesar 0.946, dan variabel terakhir yaitu loyalitas pelanggan memperoleh nilai Cronbach's Alpha sebesar 0.905. Ketiga variabel yang melibatkan seluruh item pernyataan dinyatakan memiliki reliabilitas tinggi dengan nilai > 0.70 sehingga data dapat digunakan pada tahap selanjutnya.

\section{Uji Model Pengukuran}

Uji model pengukuran dilakukan menggunakan software IBM AMOS 23, yang bertujuan untuk menguji hubungan antara indikator dengan variabel penelitian.

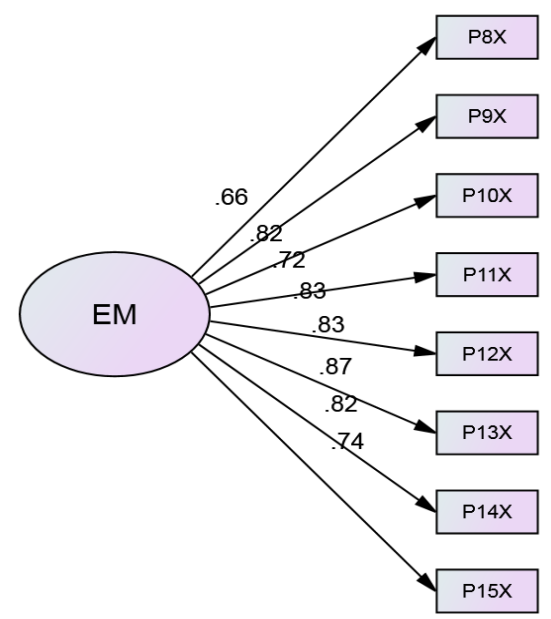

Gambar 2. Hasil Uji Model Pengukuran Variabel Experiential Marketing

Gambar 2 menunjukkan bahwa indikator P13X (pelayanan yang diberikan) memiliki factor loading yang paling besar yaitu 0.87 , hal tersebut dapat diartikan bahwa P13X merupakan indikator yang paling dominan dalam menggambarkan variabel experiential marketing. Sementara indikator P4X (aroma di dalam toko) kurang menggambarkan variabel experiential marketing karena memiliki factor loading paling kecil yaitu 0.63 . 


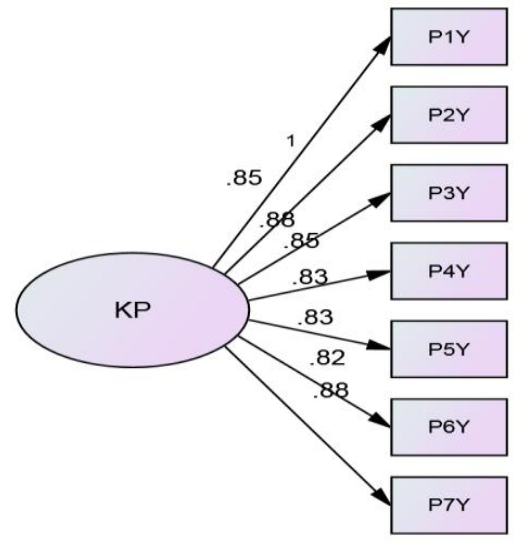

Gambar 3. Hasil Uji Model Pengukuran Variabel Kepuasan Pelanggan

Gambar 3 menunjukkan bahwa indikator P2Y (kualitas produk) dan P7Y (kesesuaian harga) memiliki factor loading yang paling besar yaitu 0.88 , hal tersebut dapat diartikan bahwa P8Y merupakan indikator yang paling dominan dalam menggambarkan variabel kepuasan pelanggan. Sementara indikator P6Y (kualitas pelayanan) kurang menggambarkan variabel kepuasan pelanggan karena memiliki factor loading paling kecil yaitu 0.82 .

Gambar 4 menunjukkan bahwa indikator P2Z dan P3Z (mengatakan hal positif dan merekomendasikan produk dan jasa kepada orang lain) memiliki factor loading yang paling besar yaitu 0.88, hal tersebut dapat diartikan bahwa P2Z dan P3Z merupakan indikator yang paling dominan dalam menggambarkan variabel loyalitas pelanggan. Sementara indikator P5Z (ketidaktertarikan pada merek lain) kurang menggambarkan variabel kepuasan pelanggan karena memiliki factor loading paling kecil yaitu 0.70 .

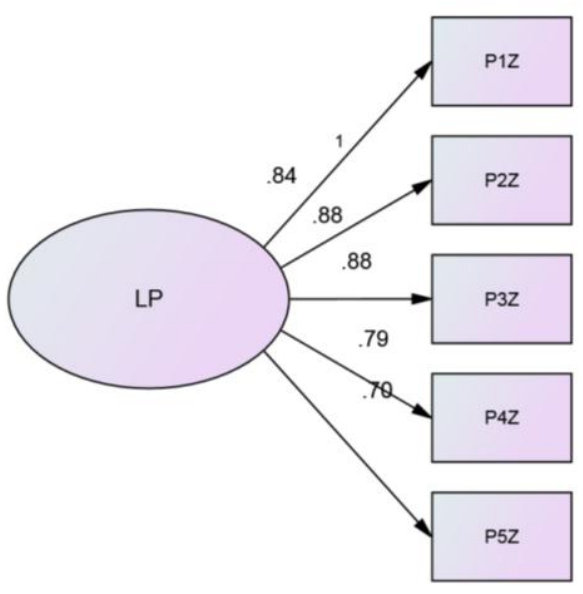

Gambar 4. Hasil Uji Model Pengukuran Variabel Loyalitas Pelanggan

Pengukuran squared multiple correlations $\left(\mathrm{R}^{2}\right)$ memiliki tujuan untuk menilai goodness of fit dari persamaan regresi yang memberikan persentase variasi total dalam variabel terikat yang dijelaskan oleh variabel bebas. Nilai $\mathrm{R}^{2}$ terletak antara $0-1$. Dan kecocokan model dikatakan lebih baik kalau nilai $\mathrm{R}^{2}$ semakin mendekati 1. Berikut gambar untuk merumuskan hasil persamaan regresi pada penelitian ini:

$$
K P=0.97 R^{2}=0.95
$$

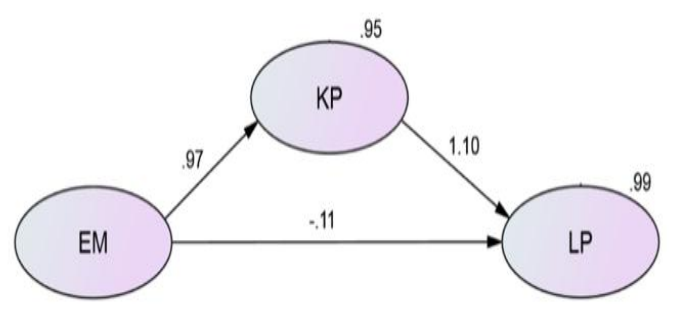

Gambar 5. Hasil Uji Persamaan Regresi $\left(\mathrm{R}^{2}\right)$

Berdasarkan persamaan pertama pada Gambar 5 diketahui bahwa variabel kepuasan pelanggan dapat diterangkan sebesar $95 \%$ oleh variabel experiential marketing, sedangkan sisanya sebesar $5 \%$ diterangkan oleh variabel lainnya yang tidak termasuk dalam model penelitian.

$$
L P=1.10 * K P-0.11 R^{2}=0.99
$$

Berdasarkan persamaan kedua dari Gambar 5 diketahui bahwa variabel loyalitas pelanggan dapat diterangkan sebesar $99 \%$ oleh kedua variabel yaitu kepuasan pelanggan dan experiential marketing, sedangkan sisanya sebesar $1 \%$ diterangkan oleh oleh variabel lainnya yang tidak termasuk dalam model penelitian.

\section{Pengaruh Langsung dan Tidak Langsung}

Analisis pengaruh langsung dan tidak langsung digunakan untuk melihat pengaruh antar variabel, baik secara langsung maupun tidak langsung. Berikut hasil nilai standardize pengaruh langsung, tidak langsung, dan total effect:

Tabel 5. Hasil Nilai Standardize Pengaruh Langsung Dan Tidak Langsung

\begin{tabular}{lccc}
\hline & Direct & Indirect & Total \\
\hline $\begin{array}{l}\text { Experiential } \\
\text { Marketing - } \rightarrow\end{array}$ & & & \\
Kepuasan & .957 & 0 & .957 \\
$\begin{array}{l}\text { Pelanggan } \\
\text { Kepuasan }\end{array}$ & & & \\
$\begin{array}{l}\text { Pelanggan - } \rightarrow \\
\text { Loyalitas }\end{array}$ & .885 & 0 & .885 \\
$\begin{array}{l}\text { Pelanggan } \\
\text { Experiential } \\
\text { Marketing - } \rightarrow\end{array}$ & & & \\
$\begin{array}{l}\text { Loyalitas } \\
\text { Pelanggan }\end{array}$ & .130 & .818 & .948 \\
\hline
\end{tabular}

Berdasarkan tabel 4.10, dapat dilihat bahwa experiential marketing memiliki pengaruh secara 
langsung terhadap kepuasan pelanggan sebesar 95,7\% (0.957), variabel kepuasan pelanggan memiliki pengaruh secara langsung terhadap loyalitas pelanggan sebesar $88,5 \%(0.885)$, dan experiential marketing memiliki pengaruh secara langsung terhadap loyalitas pelanggan (tanpa melalui kepuasan pelanggan) sebesar $13 \%$. Experiential marketing memiliki pengaruh tidak langsung terhadap loyalitas pelanggan sebesar $81,8 \%$. Sehingga dapat dilihat pengaruh experiential marketing terhadap loyalitas pelanggan akan meningkat apabila diperantarai oleh kepuasan pelanggan.

\section{Pengujian Hipotesis}

Tabel 6. Hasil Uji Hipotesis

\begin{tabular}{|c|c|c|c|c|}
\hline $\begin{array}{l}\text { Hipotesis } \\
\text { (H) }\end{array}$ & $\begin{array}{l}\text { Pernyataan } \\
\text { Hipotesis }\end{array}$ & $\begin{array}{l}\mathrm{T}- \\
\text { values }\end{array}$ & $\begin{array}{l}\mathrm{T}- \\
\text { table }\end{array}$ & Keterangan \\
\hline H1 & $\begin{array}{l}\text { Experiential } \\
\text { Marketing } \\
(\mathrm{X}) \\
\text { memiliki } \\
\text { pengaruh } \\
\text { terhadap } \\
\text { kepuasan } \\
\text { Pelanggan } \\
(\mathrm{Y}) \\
\end{array}$ & 16.33 & 1.96 & Diterima \\
\hline $\mathrm{H} 2$ & $\begin{array}{l}\text { Y memiliki } \\
\text { pengaruh } \\
\text { terhadap } \\
\text { loyalitas } \\
\text { pelanggan } \\
\text { (Z) } \\
\end{array}$ & 5.66 & 1.96 & Diterima \\
\hline H3 & $\begin{array}{l}\mathrm{X} \text { memiliki } \\
\text { pengaruh } \\
\text { terhadap Z }\end{array}$ & 0.92 & 1.96 & Ditolak \\
\hline
\end{tabular}

Tabel 7. Hasil Uji Hipotesis Variabel Intervening

\begin{tabular}{|c|c|c|c|}
\hline $\begin{array}{c}\text { Hipotesis } \\
(\mathrm{H})\end{array}$ & $\begin{array}{c}\text { Pernyataan } \\
\text { Hipotesis }\end{array}$ & Estimate & Keterangan \\
\hline \multirow[b]{2}{*}{$\mathrm{H} 4$} & $\begin{array}{l}\text { Experiential } \\
\text { marketing } \\
(\mathrm{X}) \text { memiliki } \\
\text { pengaruh } \\
\text { terhadap } \\
\text { loyalitas }\end{array}$ & $\begin{array}{l}\text { Direct }= \\
0.130\end{array}$ & \multirow{2}{*}{$\begin{array}{l}\text { Kepuasan } \\
\text { pelanggan } \\
\text { memiliki } \\
\text { pengaruh } \\
\text { tidak } \\
\text { langsung } \\
\text { terhadap } \\
\text { experiential } \\
\text { marketing } \\
\text { dan loyalitas } \\
\text { pelanggan }\end{array}$} \\
\hline & $\begin{array}{l}\text { pelanggan }(\mathrm{Z}) \\
\text { melalui } \\
\text { kepuasan } \\
\text { pelanggan } \\
(\mathrm{Y})\end{array}$ & $\begin{array}{l}\text { Indirect }= \\
0.818\end{array}$ & \\
\hline
\end{tabular}

\section{Pengaruh Experiential Marketing Terhadap Kepuasan Pelanggan}

Berdasarkan Tabel 6 , nilai $\mathrm{T}$ yang dihasilkan oleh experiential marketing terhadap kepuasan pelanggan adalah $16.33>1.96$ atau H1 diterima. Hasil penelitian ini mengindikasikan bahwa semakin tinggi nilai experiential marketing maka akan semakin meningkatkan nilai kepuasan pelanggan. Hasil hipotesis ini sesuai dengan hasil penelitian terdahulu yang dilakukan oleh Rosita (2015).

\section{Pengaruh Kepuasan Pelanggan Terhadap Loyalitas Pelanggan \\ Berdasarkan Tabel 6, nilai $\mathrm{T}$ yang dihasilkan} oleh kepuasan pelanggan terhadap loyalitas pelanggan adalah $5.66>1.96$ atau $\mathrm{H} 2$ diterima. Hasil penelitian ini mengindikasikan bahwa semakin tinggi nilai kepuasan pelanggan maka akan semakin meningkatkan nilai loyalitas pelanggan. Hasil hipotesis ini sesuai dengan penelitian terdahulu yang dilakukan oleh Widowati \& Tsabita (2017).

\section{Pengaruh Experiential Marketing Terhadap Loyalitas Pelanggan}

Berdasarkan Tabel 6, nilai $\mathrm{T}$ yang dihasilkan oleh experiential marketing terhadap loyalitas pelanggan adalah $0.92<1.96$ atau H3 ditolak. Hasil penelitian ini mengindikasikan bahwa experiential marketing tidak berpengaruh secara signifikan terhadap loyalitas pelanggan. Hasil hipotesis ini tidak sesuai dengan penelitian terdahulu yang dilakukan oleh Dewi et al. (2015) dan Setiobowo (2017), namun sesuai dengan penelitian terdahulu yang dilakukan oleh Widowati \& Tsabita (2017)

Pengaruh Experiential Marketing Terhadap Loyalitas Pelanggan melalui Kepuasan Pelanggan

Berdasarkan Tabel 7, kepuasan pelanggan sebagai variabel intervening antara variabel experiential marketing dan loyalitas pelanggan memiliki nilai tidak langsung lebih tinggi dari nilai secara langsung, dengan nilai 0.130 atau $13 \%$ dan nilai tidak langsung sebesar 0.818 atau $81,8 \%$. Hal ini mengindikasikan bahwa variabel intervening yaitu kepuasan pelanggan berperan sebagai mediasi antara experiential marketing dan loyalitas pelanggan. Hasil hipotesis ini sesuai dengan penelitian terdahulu yang dilakukan oleh Widowati dan Tsabita (2017).

\section{PEMBAHASAN}

Penelitian ini memilki jawaban yang bervariasi pada masing-masing pernyataan yang telah dijawab oleh responden. Penggunaan model pengukuran pada penelitian secara keseluruhan memiliki tingkat kesesuaian yang baik. Pada uji hipotesis 1 (H1), experiential marketing berpengaruh terhadap kepuasan pelanggan. Hal ini berdasarkan hasil Tabel 6, yang mana nilai $\mathrm{T}$ yang dihasilkan oleh experiential marketing terhadap kepuasan pelanggan adalah $16.33>1.96$. Berdasarkan lima aspek yang dimiliki oleh experiential marketing yaitu sense, feel, think, act, dan relate dapat menciptakan kepuasan melalui emosi yang tumbuh pada diri pelanggan.

Berdasarkan karakteristik responden pada penelitian ini jika dilihat dari rata-rata pengeluaran per bulan, responden memilki rata-rata pengeluaran per bulan sebesar 1-5 juta. Dari hasil karakteristik responden tersebut dapat dinyatakan bahwa responden merupakan pelanggan yang mencari 
produk dengan harga rendah tetapi memiliki kualitas yang bagus sehingga produk bisa dipakai dalam jangka waktu yang lama.

Pada uji hipotesis 2 (H2), kepuasan yang dimiliki oleh pelanggan dapat membuat pelanggan menjadi loyal. Hal ini berdasarkan hasil Tabel 6, yang mana nilai $\mathrm{T}$ yang dihasilkan oleh kepuasan pelanggan terhadap loyalitas pelanggan adalah 5.66 $>$ 1.96. Loyalitas pelanggan akan tinggi apabila suatu produk dinilai mampu memberi kepuasan tertinggi sehingga pelanggan enggan untuk beralih ke merek lain. Terpenuhi nya harapan yang dimiliki oleh pelanggan maka dapat membentuk loyalitas yang kuat pada diri pelanggan, sehingga pelanggan akan semakin sering untuk menggunakan barang dan jasa yang dimiliki oleh perusahaan dan bersedia untuk merekomendasikan kepada orang lain.

Pada uji hipotesis $3(\mathrm{H} 3)$, dengan menerapkan experiential marketing tidak memberikan pengaruh terhadap loyalitas pelanggan secara langsung. Hal ini berdasarkan pada hasil Tabel 6 , yang mana nilai $\mathrm{T}$ yang dihasilkan oleh experiential marketing terhadap loyalitas pelanggan adalah $0.92<1.96$. Pelanggan harus merasakan dan memiliki rasa puas terlebih dahulu sebelum memutuskan menjadi loyal terhadap perusahaan. Hal ini sesuai dengan pernyataan yang dinyatakan oleh Tjiptono (2010:107) (dalam Sari et al., 2017). Tjiptono menyatakan bahwa loyalitas pelanggan terbentuk karena pelanggan merasakan kepuasan dalam mengkonsumsi barang atau jasa.

Pada uji hipotesis $4(\mathrm{H} 4)$, kepuasan pelanggan memiliki pengaruh tidak langsung terhadap experiential marketing dan loyalitas pelanggan. Dengan hasil nilai standardized indirect effect lebih besar dari hasil nilai standardized direct effects yaitu 0.818 menunjukkan bahwa kepuasan pelanggan berperan sebagai mediasi antara variabel experiential marketing dan loyalitas pelanggan.

\section{KESIMPULAN}

Berdasarkan hasil analisis data yang dilakukan, dapat ditarik beberapa kesimpulan pada penelitian ini, antara lain: Experiential marketing memiliki pengaruh positif dan signifikan terhadap kepuasan pelanggan dan kepuasan pelanggan tersebut memiliki pengaruh positif dan signifikan terhadap loyalitas pelanggan. Selanjutnya Experiential marketing memiliki pengaruh positif dan tidak signifikan terhadap loyalitas pelanggan. Penelitian ini membuktikan experiential marketing tidak memiliki pengaruh langsung terhadap loyalitas pelanggan, tetapi Experiential marketing ditemukan memiliki pengaruh terhadap loyalitas pelanggan melalui kepuasan pelanggan.

Kepuasan pelanggan dinilai berperan penting sebagai perantara antara variabel experiential marketing dan loyalitas pelanggan oleh karena itu perusahaan pada indsutri ritel diharapkan dapat mempertahankan dan meningkatkan kepuasan pelanggan dengan selalu memperhatikan experiential marekting yang diberikan kepada pelanggannya.

\section{DAFTAR PUSTAKA}

ATKearny (2019). The 2019 Global Retail Development Index TM: ATKearney. (2017). The 2017 Global Retail Development Index ${ }^{\mathrm{TM}}$. The Age of Focus. ATKearney.

Barata, D. D. (2016). The impact of leader engagement on creation of innovation culture. International Journal of Economics and Management, 10(S1), 135-149

Barata, Dion Dewa and Agatha Febriyanti Napitupulu, (2019), "Why We Switch from Conventional to Sharia Bank?" in International Conference on Economics, Management, and Accounting, KnE Social Sciences, pages 160-174. DOI 10.18502/kss.v3i26.5371

Barimbing, C. A., \& Sari, D. (2015). "Pengaruh Experiental Marketing Terhadap Kepuasan Pelanggan" (Studi pada Pelanggan Mujigae Resto Ciwalk Bandung). 772.

Budiarta, S. I., \& Fachira, I. (2017). Customer Loyalty: The Effects Of Service Loyalty And The Mediating Role Of Customer Satisfaction Study Case: Pt Sabda Alam Hotel. Journal of Business and Management, 251.

Dewi, R. K., Kumadji, S., \& Mawardi, M. K. (2015). Pengaruh Experiential Marketing Terhadap Kepuasan Pelanggan Dan Dampaknya Pada Loyalitas Pelanggan (Survei Pada Pelanggan Tempat Wisata Jawa Timur Park 1 Kota Wisata Batu). Jurnal Administrasi Bisnis (JAB), 2.

Eka, M. R., \& Yuliana, E. (2016). Pengaruh Experiential Marketing Terhadap Kepuasan Pelanggan (Studi Pada Wiki Koffie Bandung). 250.

Hadiwidjaja, R. S., \& Dharmayanti, D. (2015). Analisa Hubungan Experiential Marketing, Kepuasan Pelanggan, Loyalitas Pelanggan Starbucks Coffee di Surabaya Town Square. Jurnal Manajemen Pemasaran, 2, 3.

Kotler, P., \& Keller, K. L. (2016). Marketing Management. Harlow: Pearson Education Limited.

Pangastuti, R. L. (2017). The Influence of Experiential Marketing and Service Quality For being Reasonability of Customers Loyality Forming (Case Study of Beauty Saloon of London Beauty Center "LBC"). Jurnal Ekonomi Universitas Kadiri, 202.

Rosita, N. S. (2015). Pengaruh Experiential Marketing Terhadap Kepuasan Pelanggan Swalayan Sinar Rahayu Negara Tahun 2014.

Sari, H. P., Rachma, N., \& Priyono, A. A. (2017). Pengaruh Experiential Marketing Terhadap Loyalitas Dengan Kepuasan Pengunjung Sebagai Variabel Intervening (Studi Pada Merbabu Guest House Di Kota Malang). Riset Manajemen Prodi Manajemen.

Schmitt, B., \& Rhea, D. (2015). Experiential Marketing: A New Framework for Design and Communications. Design Management Review.

Schmitt, B., \& Zarantonello, L. (2013). Consumer Experience And Experiential Marketing: A Critical Review.

Setiobowo, R. (2017). The Influence of Experiential Marketing, Service Quality on Customer Loyalty and Satisfaction at the Pizza Hut Restaurant in the 
Tunjungan Plaza Surabaya. Advances in Economics, Business and Management Research (AEBMR), 35.

Smith, K., \& Hanover, D. (2016). Experiential Marketing: Secrets, Strategies, and Success Stories from the World's Greatest Brands. Canada: Wiley.

Widowati, R., \& Tsabita, F. (2017). The Influence Of Experiential Marketing On Customer
LoyaltyThrough Customer Satisfaction As Intervening Variable (Study at The House of Raminten Resturant in Yogyakarta Indonesia). 168.

Zati, M. R., \& Iqbal, M. (2017). Pengaruh Pengalaman Terhadap Loyalitas Konsumen di Alfamart Langsa. Jurnal Samudra Ekonomi dan Bisnis, Vol 8, No.2 Juli 201 